\title{
TRAJETÓRIA FORMATIVA: ENTRELAÇANDO SABERES... ESTUDO DO MEIO COMO LUGAR DE APRENDIZAGEM DO/DISCENTE
}

\author{
Giovanna Marget Menezes Cardoso* \\ Recebido em: 03 de maio de 2009 Aprovado em: 02 de junho de 2009
}

*Professora da Universidade do Estado da Bahia - UNEB. Aluna do Mestrado em Inovação Pedagógica pela Universidade de Madeira - Portugal. E-mail: margett@ig.com.br

Resumo: As reflexões propostas neste artigo são em decorrência de uma prática educativa que visa fazer do processo de ensinagem na sala de aula, um espaço de pesquisa. Tal proposta de trabalho tem viés nos estudos do componente curricular Fundamentos da Educação Infantil, a qual é oferecida no quinto semestre do curso de Licenciatura em Pedagogia da Universidade do Estado da Bahia / UNEB - Campus XI, Serrinha/BA. Nesta perspectiva vivenciar uma prática educativa que reconheça a pesquisa como um princípio não só científico, mas, também educativo, podendo ser colocado como um paradigma da metodologia de ensino e aprendizagem. Para que este paradigma possa se desenvolver se faz mister considerar que a pesquisa alimenta-se de questionamentos elaborados, que devam ter como premissa a argumentação, fundamentação e manejo crítico do já conhecido. A abordagem metodológica se se fundamenta na perspectiva sócio-interacionista, com reflexões teóricas e trabalho de campo, tendo como instrumentos de coleta de dados a observação e entrevista. Os estudos teóricos e os dados coletados em campo permitiram comparar, elaborar hipóteses e organizar/sistematizar a realidade estudada/investigada. Os resultados evidenciam as contribuições da experiência em pesquisa no avanço/amadurecimento profissional dos educandos. Numa produção muito significativa, como resultado final os educandos apresentam o simpósio, fica explicito, nas comunicações, a percepção de que o objetivo maior da pesquisa no processo de ensino é fazer dos educandos um parceiro de trabalho ativo, participativo, produtivo e re-construtivo.

Palavras-chave: Pesquisa. Prática pedagógica. Ensino e aprendizagem.

THE TRAJECTORY OF EDUCATION: INTERTWINING KNOWLEDGES... STUDY OF THE ENVIRONMENT AS A PLACE OF LEARNING FOR THE STUDENTS AND TEACHERS

\begin{abstract}
The proposed ideas in this article are due to an educational practice that aims to make the teaching process in the classroom an area of research. The proposed work takes its vantage point from studies of the curriculum component of the Child Education Foundations, which is offered in the fifth semester of the Pedagogy Bachelor program at the University of Bahia / UNEB - Campus XI, Serrinha / BA-Brazil. In this perspective a practical educational experience to recognize the research not only as a scientific principle but also an educational one can be placed as a paradigm of the methodology of teaching and learning. In order for this paradigm to be developed it is essential to consider that research needs prepared questions, which must be based on the argument, reasoning and critical management of the already known. The methodological approach is based on the socio-interactions perspective, with theoretical and fieldwork, using observations and interviews as tools for collecting. The theoretical studies and data collected in the field allowed us to compare, develop hypotheses and organize/systematize the reality studied/investigated. The results highlight the contributions of research experience in the professional growth of the students. As a final result the students present a symposium, and it becomes explicit in their communication the perception that the prime objective of research in the teaching process is to make the students hands-on, productive, constructive working partners.
\end{abstract}

Key words: Research. Teaching. Teaching and learning.

\section{Contextualizando a discussão...}

Escrevo porque à medida que escrevo vou me entendendo e entendendo o que quero dizer, entendo o que posso fazer. 
Escrevo porque sinto necessidade de aprofundar as coisas, de vê-las como realmente são...

Clarice Lispector

Na busca de transformar a sala de aula num espaço de pesquisa, no processo de ensinagem, mediante o argumento de que por ter como característica emancipação a educação exige a pesquisa como seu método formativo, por razão principal que somente um ambiente de sujeitos gesta sujeitos. É partindo dessa premissa que o estudo do meio, é utilizado como perspectiva metodológica. Numa prática pedagógica que permite ao educando sentir-se protagonista de suas construções e refletir sobre o papel da pesquisa como prática no contexto da formação inicial. Portanto, o estudo do meio é a metodologia escolhida para tratar do tema: As políticas públicas para a Educação Infantil no Brasil: contexto de realidade, no componente curricular Fundamentos da Educação Infantil, do curso de Pedagogia da UNEB - Universidade do Estado da Bahia, Campus XI- Serrinha. Esta proposta metodológica se propõe a pensar no educador que "ensina" e ao mesmo tempo faz pesquisa, como forma deste profissional formar-se enquanto investigador da sua própria prática e reconstruir constantemente sua atividade e seus saberes docentes.

$\mathrm{Na}$ busca de uma prática que possibilite a pesquisa como metodologia de trabalho:

[...] percorremos certos caminhos que nos dão certa segurança, porque não há conhecimento absoluto e definitivo, Eles são sempre relativizados sintetizados sob certas condições, dependendo das teorias e métodos que o pesquisador escolhe, devendo essas ter coerência entre si. Fazer pesquisa é fazer escolhas. Não há um modelo de pesquisa científica, nem o método científico, há sim caminhos já trilhados por pesquisadores experientes que nos ajudam a trilhar os nossos com maior segurança. Tendo em vista que o próprio pesquisador apresenta em seu trabalho comportamentos e visões peculiares. Assim, o conhecimento obtido pela pesquisa é um conhecimento situado - através de momentos históricos e das escolhas e olhares do pesquisador, qualquer que seja a natureza desses dados. (ILHA, 2008, p. 2)

Desse modo o "ensino" por meio da metodologia da pesquisa, possibilita-se aos sujeitos imbricados a percorrer caminhos na busca de produção do conhecimento. Que ao mesmo tempo em que é desvelado, aparece como uma "certeza", bem como aparece como um olhar que é nosso, e que, portanto pode e deve ser relativizado, pois é apenas outro modo de ler/interpretar/perceber a "realidade".

Paulo Freire (1996), em sua obra Pedagogia da Autonomia, preconiza: para que possamos verdadeiramente ser aprendiz, devemos exercer criticamente a 
capacidade de aprender. Ser aprendiz na concepção freiriana é se construir e desenvolver a curiosidade epistemológica, o papel do verdadeiro educador é reforçar a capacidade crítica do educando, para tanto, é imprescindível que o mesmo tenha a pesquisa como base metodológica de desenvolvimento do seu trabalho.

Desse modo é preciso salientar que:

[...] o profissional da educação, cada vez mais sente necessidade de ter contato maior com teorias, pensamentos e edificações teóricometodológicas que venham contribuir para a ressignificação da prática pedagógica. Nesse contexto, os cursos de formação de educadores precisam estar atentos á importância da pesquisa para a produção intelectual, pois pesquisar é um ato cognitivo que exige um pensamento mais elaborado, sistematizado; que faz o sujeito transpor limites e adquirir sustentação para qualificar a ação. (PEREIRA; FONSECA, 2007 p. 3)

Para que o profissional da educação possa ressignificar a prática pedagógica, ele necessita refletir sobre a mesma, bem como trabalhar com uma metodologia que possibilite ao mesmo a qualificação da sua prática, e a pesquisa é uma perspectiva metodológica que permite o dialogo entre teoria e prática, qualificando a ação pedagógica. Ainda, conforme Demo (2005, p. 05), a proposta de educar pela pesquisa tem quatro pressupostos cruciais, a saber:

1. A convicção de que a educação pela pesquisa é especificamente mais própria da educação acadêmica;

2. O reconhecimento de que o questionamento re-construtivo com qualidade formal e política é o cerne do processo da pesquisa;

3. A necessidade de fazer da pesquisa atitude cotidiana no educador e no educando;

5. E a definição de educação como processo de formação da competência histórica humana.

Partindo dessa análise, a prática pedagógica desenvolvida no componente curricular Fundamentos da Educação Infantil busca articular o discurso da academia à realidade sócio-educacional, por meio da pesquisa.

Desse modo, o estudo do meio organiza-se, a partir dos conteúdos abordados no componente curricular em questão, em que educador/mediador promove uma vasta e consistente discussão/reflexão à luz dos teóricos, junto com os educados/aprendizes, numa prática dialógica de análise e sistematização; num processo dialético de desconstrução e reconstrução de conceitos/concepções, como fruto das reflexões em sala de aula, buscando, deste modo, construir uma base teórica que dê sustentação as indagações. Num segundo momento, 
os conteúdos a se trabalhar são sistematizados, sem, contudo, procurar que se esgotem, "nada pode ser totalmente entendido" (DEMO, 2005, p. 31), na perspectiva de buscar compreender a "realidade" posta e numa expectativa que corresponda a uma inovação, no sentido de reconstruir o conhecimento e quiçá desconstruir o que existe para reconstruir em outro nível.

A partir das discussões, resultado do diálogo com os teóricos que discutem sobre a temática, do levantamento de hipóteses e da sistematização, os educandos/aprendizes, divididos/organizados em grupos para planejar toda a ação que norteia o estudo do meio. Cada grupo tem a sua temática demarcada, a saber: Diretriz Curricular/PARECER CNE/CEB 22/1998; Diretrizes Operacionais para a Educação Infantil; RCNEI - Referencial Curricular para a Educação Infantil; Objetivos da Educação Infantil; RCNEI - Estratégias e Orientações para a educação de crianças com necessidades educacionais especiais; Orientações e ações para a educação das relações étnico-racias - Educação Infantil; O profissional da Educação Infantil, perspectivas e desafios e Instituições de Educação Infantil: Concepções.

A partir dos temas produzem-se os instrumentos de coleta de "dados" indo ao lócus de pesquisa fazer a coleta, e de posse dos mesmos, em sala de aula, parti-se para a análise e reflexão dos "dados" a luz do referencial teórico, tece-se considerações a partir de argumentações, que revelam a habilidade estabelecer relações e de tecer textos em profundidade, competência metodológica para ordenar o tema e oferecer-lhe um corpus elaborado.

Os educandos fazem as articulações/análises entre os "dados" e o referencial teórico e após as reflexões, articulações e refacções, a culminância do estudo se dá num simpósio com regras pré-estabelecidas dentro dos rigores acadêmicos, aberto à comunidade universitária e externa. As apresentações dos resultados da ação são ricas e provocam um debate intenso e envolvente, em que os participantes, tanto os que apresentam como os que assistem, expressam a riqueza da experiência e evidenciam o amadurecimento a partir de tal intento.

Nesta perspectiva metodológica pode-se vislumbrar como fulcro, a importância das historicidades, dos nexos, da rede teórica, da análise e reflexão, dos elementos que possibilitam a síntese obtida. Como afirma Anastasiou (2003, p. 13), "a ausência desses aspectos científicos, sociais e históricos deixa os conteúdos soltos, fragmentados, com fim e si mesmos".

\section{Conceituando: O Estudo do meio...}

A aventura de partir à descoberta para conhecer o Meio - no sentido de saber pensar e atuar sobre ele - pressupõe o desenvolvimento de competências especificas em três grandes 
domínios que se relacionam entre si: a localização no espaço e no tempo; o conhecimento do ambiente natural e social e o dinamismo das inter-relações entre o natural e o social. A localização no espaço e no tempo Priscila Maria Farah

O estudo do meio, como perspectiva metodológica, escolhida com o objetivo de desenvolver uma prática pedagógica que supere a idéia do simples dizer do conteúdo, num processo que possibilite "destacar o aspecto do saber referente ao gosto ou sabor, do latim sapere - ter gosto. Na ensinagem, o processo de ensinar e aprender exige um clima de trabalho tal que possa saborear o conhecimento em questão", (grifo nosso). (ANASTASIOU, 2003, p. 12)

O estudo do meio por ter como operação de pensamento dominante a obtenção de dados/crítica comparação/elaboração de hipóteses/ organização de dados. Possibilita a superação das questões supracitadas, numa prática pedagógica que vai além de um ensino fragmentado e descontextualizado, provocando no educando o desejo de conhecer e desnudar a realidade, na ânsia de melhor conhecê-la, para nela atuar.

O Meio, neste contexto compreendido como um conjunto de elementos, fenômenos, acontecimentos, fatores e / ou processos diversos, que ocorrem no meio vivido, é onde a vida e a ação das pessoas têm lugar e adquirem significado. Portanto, podemos afirmar que o Meio desempenha um papel condicionante e determinante na vida, experiência e atividade humanas, ao mesmo tempo em que sofre transformações contínuas como resultado dessa mesma atividade. Vale ressaltar, que o mesmo explicita as relações dos sujeitos nos mais variados espaços, desse modo o conhecimento/ desvelamento do meio a partir da observação, reflexão e análise dos fenômenos, dos fatos e das situações, permite uma melhor compreensão dos fotos sociais e políticos que permeiam o Meio, o que possibilita ao sujeito a condução de intervenção crítica no mesmo.

Intervir criticamente significa ser capaz de analisar e conhecer as condições e as situações em que somos afetados pelo que acontece no meio e significa também intervir no sentido de modificar, o que implica processos de participação, defesa e respeito. Estudar o meio pressupõe, então, a emergência de componentes emocionais, afetivos e práticas de relação com ele, proporcionadas pela vivência de experiências de aprendizagem que promovam o desenvolvimento de competências específicas no âmbito da área disciplinar.

[...] o pesquisador estará sempre buscando novas respostas e novas indagações para o desenvolvimento do seu trabalho; valorizando a interpretação do contexto; retratando a realidade de forma densa, refinada e profunda; estabelecendo planos de relações com o objeto 
pesquisado, revelando-se aí a multiplicidade de âmbitos e referências presentes em determinadas situações ou problema; usando uma variedade de informações. (MACEDO, 2006, p. 89)

A partir das suas percepções, vivências e representações, o educando é levado à compreensão, à reelaboração, à tomada de decisões e à adoção de uma linguagem progressivamente mais rigorosa e científica. Isto significa que os educandos trazem para o espaço acadêmico um conjunto de idéias, preconceitos, representações, disposições emocionais e afetivas e modos de ação próprios.

Podemos inferir que esse corpo de conhecimento trazido pelos educandos ao ingressarem na academia, são esquemas de conhecimento subjetivos, incoerentes, pouco maduros e incapazes de captar a complexidade do meio tal como este se apresenta à experiência humana. Estes esquemas, quando confrontados com outros mais objetivos, socialmente partilhados e decorrentes do processo de ensino vão sofrendo rupturas que abalam a visão sincrética da realidade, a perspectiva egocêntrica e as explicações mágicas e finalísticas que são próprias do pensamento do senso comum, como afirmava Paulo Freire (1996), dando origem a um conhecimento cada vez mais rigoroso e científico, um conhecimento epistemológico.

\section{Questão fundamental para a docência: Ensino e Pesquisa.}

Pensar certo - e saber que ensinar não é transferir conhecimento é fundamentalmente pensar certo - é uma postura exigente, dificil, às vezes penosa, que temos de assumir diante dos outros e com os outros, em face do mundo e dos fatos, ante nós mesmos.

Paulo Freire

Falar em produção do conhecimento é estar nos referindo à pesquisa como seu sinônimo. Assim, coadunando com as idéias de Demo (2005, p. 14), "a premissa de que não se pode conceber educador que apenas exerça o ensino; do mesmo modo, que dificilmente se pense num pesquisador que apenas pesquise sem socializar os resultados de sua busca". Nessa perspectiva, acreditamos ser fulcral que haja uma articulação/imbricação entre as duas esferas (ensino e pesquisa), e é nesta articulação que reside à produtividade docente.

Paulo Freire (1996, p. 29), ao escrever a Pedagogia da Autonomia aborda a questão supracitada de um modo bem simples e objetivo:

Fala-se hoje, com insistência, no professor pesquisador. No meu entender o que há de pesquisador no professor não é uma qualidade ou uma forma de ser ou de atuar que se acrescente a ensinar. Faz parte da natureza da prática docente a indagação, a busca, a pesquisa. $\mathrm{O}$ 
que se precisa é que, em sua formação permanente, o professor se perceba e se assuma, porque professor, como pesquisador.

Ao colocar a pesquisa como condição e responsabilidade indispensáveis da ação docente, apontamos como conseqüência que a mesma, tanto para o educador quanto para o educando, torna-se um princípio educativo, uma vez que o professor não educa apenas através de palavras, mas, também, pela postura revelada em suas atitudes. Como bem afirma Freire (1996, p. 34), "ensinar exige a corporeificação das palavras pelo exemplo", (grifo nosso).

Assim estabelecer a pesquisa como princípio educativo também significa incentivar a capacidade de questionamento crítico do educando; fazer com que ele consiga identificar as fontes de informação e conhecimento que podem ser utilizadas para levar o processo de pesquisa a bom termo (bibliotecas, acervos culturais, museus, internet, in lócus); aguçar a capacidade de selecionar e manusear informações; incentivar o uso da tecnologia disponível; possibilitar uma postura cientifica para o tratamento metodológico das questões. Nessa medida, o verdadeiro educador não pensa a construção do conhecimento fora da relação com a vida social, haja vista que a prática pedagógica, para ser eficaz, pede esta articulação com a concretude do sujeito e do real.

[...] construir conhecimento é principalmente ter idéias próprias, sínteses pessoais, modo particular de ver, atenção observadora, análise crítica do que acontece e assim por diante. No professor não basta isso. É mister que ele elabore teoricamente e que teorize as práticas. (DEMO, 1992, p. 8)

Nesse viés, preconiza-se uma educação que promova uma tentativa constante de mudança de atitude no sujeito, substituindo a passividade pelo hábito da participação e ingerência. Contudo no modelo educacional contemporâneo, nas práticas pedagógicas adotadas de modo geral, nada faz para alcance de tal objetivo.

[...] Não seria, porém, quase nada existe em nossa educação, que desenvolva no nosso estudante o gosto da pesquisa, da constatação, da revisão dos "achados" - o que implicaria no desenvolvimento da consciência transitivo-crítica. Pelo contrário, a sua consciência ingênua $[\ldots]$

[...] Cada vez mais nos convencemos, aliais, de se encontrarem na nossa inexperiência democrática, as raízes deste nosso gosto da palavra oca. Do verbo. Da ênfase nos discursos. Do torneio da frase. É que toda esta manifestação oratória, quase sempre também sem profundidade, revela, antes de tudo, uma atitude mental. Revela ausência de permeabilidade característica da consciência crítica. E é precisamente a criticidade a nota fundamental da mentalidade democrática. 
Esta nos parecia uma das grandes características de nossa educação. A de vir enfatizando cada vez mais em nós posições ingênuas, que nos deixam sempre na periferia de tudo o que tratamos. Pouco ou quase nada, que nos leve a posições mais indagadoras, mais inquietas, mais criadoras. Tudo ou quase tudo nos levando, desgraçadamente, pelo contrário, à passividade, ao "conhecimento", memorizado apenas, que, não exigindo de nós elaboração ou reelaboração, nos deixa em posição de inautêntica sabedoria. (FREIRE, 1996, p. 102-104 )

\section{A práxis: prática pensada e refletida, transformada em ação.}

[...] Não é possível também formação docente indiferente à boniteza e à decência que estar no mundo, com o mundo e com os outros, substantivamente, exige de nós. Não há prática docente verdadeira que não seja ela mesma um ensaio estético e ético.

Paulo Freire

Mediar as descobertas dos educandos no que se refere à metodologia de trabalho com o estudo do meio, sem dúvidas, é uma experiência rica e interessante que proporciona a construção do conhecimento, o qual permeado pela pesquisa e reflexão, atribuição de sentido às informações construídas em sala de aula, aos textos lidos e debatidos, aos saberes analisados. A aprendizagem se concretiza quando transformamos as informações em conhecimento, transformando à "curiosidade ingênua" em "curiosidade epistemológica". (FREIRE, 1997, p. 13, grifo nosso)

Os aprendizes / educandos produziram vídeos, textos, painéis eletrônicos, estabeleceram relações (interdisciplinaridade), principalmente no tocante ao estudo do componente curricular Fundamento da Educação Infantil. O estudo está contribuindo para a compreensão de que a construção de Políticas Públicas para Educação Infantil deva ser consubstanciada nos princípios de cidadania, esta compreendida aqui, não apenas enquanto direitos e deveres da criança, mas que perpassa a dimensão ética e política.

Nas falas dos educandos, podemos perceber a riqueza da experiência com estudo do meio, culminando no simpósio:

O que eu mais gostei na atividade do estudo do meio foi a articulação entre teoria e prática, a produção do conhecimento, ao educador interagindo com o educando, provocando, instigando ao educando a produção do conhecimento (aluna $-5^{\circ}$ semestre do curso de Pedagogia -2008)

O fato de termos ido a campo com o objetivo de analisar a realidade e confronta-la com o proposto na Lei com relação aos espaços de Educação Infantil, pois saber que existe uma diretriz operacional 
de construção desses espaços e que os mesmos devem ser pensador a partir da colaboração de uma equipe multidisciplinar foi uma descoberta importante. O estudo do meio foi uma prática que alargou os nossos conhecimentos em relação E.I. pois através dele, das aulas e das pesquisas realizadas nas escolas, e nas secretarias municipais de educação, numa relação entre teoria e prática foi possivel percebermos os pontos avanços e retrocessos que permeia a E.I., as possibilidades que existem [...] as possibilidades para uma efetivação de uma educação de qualidade para esse público [...] (aluna $-5^{\circ}$ semestre do curso de Pedagogia - 2008)

[...] Sem dúvida o processo de pesquisa, analise e estudo do meio e a elaboração e concretização do Simpósio, proporcionou a todos, a oportunidade de ampliar a visão de modo critico, sobre as políticas educacionais para a Educação Infantil, foi de grande valia para nossa formação, como futuros Pedagogos e como pessoa. (aluna $-5^{\circ}$ semestre do curso de Pedagogia - 2008)

Diante das falas dos educandos, extraídas do relatório final sobre o estudo do meio, evidencia-se o quanto esta metodologia possibilita uma prática pedagógica critica, reflexiva e criativa e que, como diria Freire, envolve o movimento dialético entre o fazer e o pensar sobre o pensar e o fazer.

\section{Ponderações conclusivas...}

À medida que a leitura interpretativa dos "dados" se dá - às vezes por várias oportunidades - aparecem significados e acontecimentos, recorrências, índices representativos de fatos observados, contradições profundas, relações estruturadas, ambigüidades marcantes. Roberto Sidnei

Caminhante, é o teu rasto o caminho, e nada mais; caminhante, não há caminho, o caminho faz-se ao caminhar.

Antonio Machado

É importante dar-se conta de que, na contemporaneidade, "a pedagogia das certezas está sendo substituída por uma pedagogia do problema", onde o saber pré-fixado cede lugar à busca da informação para a construção contínua do conhecimento. Portanto, a perspectiva metodológica do estudo do meio possibilita que o educador em vez de dar respostas prontas, problematize os conteúdos previstos no componente curricular - Fundamentos da Educação Infantil, numa prática pedagógica que media às descobertas dos educandos na construção do conhecimento, permeada pela pesquisa e reflexão. 
A prática resulta numa produção muito significativa, a apresentação do simpósio, em que os educandos explicitam, nas comunicações, a percepção de que o objetivo maior da pesquisa no processo de ensino é fazer dos mesmos um parceiro de trabalho ativo, participativo, produtivo e re-construtivo. Nesse sentido Freire (1979, p. 28), salienta que:

[...] no processo de aprendizagem, só aprende verdadeiramente aquele que se apropria do aprendido, transformando-o em apreendido, [...] Aquele que é "enchido" por outro de conteúdo cuja inteligência não percebe; de conteúdos que contradizem a forma própria de estar em seu mundo, sem que seja desafiado, não aprende.

Nesses termos, é preciso explicitar as habilidades e competências demonstradas pelos educandos visualizadas ao longo da experiência e que merecem destaque:

$\checkmark$ Um envolvimento mais intenso dos educandos no componente curricular;

$\checkmark$ A percepção da importância da localização no espaço e no tempo do conhecimento do ambiente natural e social e o dinamismo das interrelações entre o natural e o social;

$\checkmark$ Efetiva participação dos educandos nas atividades de grupo, adotando um comportamento construtivo, responsável e solidário, valoriza as contribuições de cada um em função de objetivos comuns e o respeito aos princípios básicos do funcionamento democrático;

$\checkmark$ No decorrer da apresentação do trabalho a capacidade de exprimir, fundamentar e discutir as idéias pessoais sobre fenômenos e problemas do meio físico e social com vista a uma aprendizagem cooperativa e solidária;

$\checkmark$ A habilidade de utiliza formas variadas de comunicação escrita, oral e gráfica e aplicar técnicas elementares de pesquisa, organização e tratamento de dados;

$\checkmark$ A capacidade de investigar e descobrir e utilizar processos científicos na realização de atividades experimentais;

$\checkmark$ A capacidade de identificar os principais elementos do meio físico e natural, analisar e compreender as suas características mais relevantes e o modo como se organizam e interagem, tendo em vista a evolução das idéias pessoais na compreensão do meio envolvente;

$\checkmark$ Maior estímulo nas leituras dos textos do componente curricular;

$\checkmark$ Uma postura mais amadurecida dos educandos quanto à vida acadêmica;

$\checkmark$ A vinculação dos educandos a realidade concreta, e uma discussão sobre a mesma a luz dos elementos teóricos que as compõem;

$\checkmark$ A percepção da necessária revisão sobre os dados da teoria que fundamentam o objeto de estudo; 
A percepção da importância dos estudos teóricos para maior compreensão da realidade em permanente diálogo com a realidade concreta;

$\checkmark$ A possibilidade de produção de conhecimento por parte dos educandos por meio da articulação teoria e prática;

$\checkmark$ A aplicação de fatos a novas situações, com revisão de hipóteses, organização e reorganização de dados;

$\checkmark$ A preparação dos educando para se flexibilizar lidando com abertura diante do inesperado e de novos elementos apresentados pela realidade dinâmica;

$\checkmark$ A assunção por parte dos educandos da pesquisa como uma prática necessária do educador;

$\checkmark$ A percepção da Educação Infantil como um direito e que o educador da E.I. necessita fundamentar sua prática.

Podemos confirmar os aspectos supra citados, no registro das falas dos educandos, o quanto a perspectiva metodológica do estudo do meio promove a construção do conhecimento por parte dos educandos e o alcance dos objetivos traçados pela educadora ao planejar a atividade:

A atividade do estudo do meio foi uma experiência válida, mais interessante ainda foi à realização do simpósio, que nos mostrou que nós somos capazes de ousar e vencer desafios. Trouxe também um vasto conhecimento quando confrontou teoria e prática, quando fomos a campo conhecer os programas e ver comó é a sua realidade, os seus pontos de convergências e congruências. (aluna $-5^{\circ}$ semestre do curso de Pedagogia - 2008)

O que mais gostei de fazer nesse trabalho do estudo do meio, foi a possibilidade de poder ter conhecimento de coisas que eu não sabia, como por exemplo, que existe um documento que orienta a construção e organização das instituições de Educação Infantil, e o mais surpreendente é que as Secretarias Municipais não tomam conhecimento do documento, sou professora da E.I. e não sabia desse documento, esse fato me levou a querer pesquisar sobre o tema, estava sem saber o que pesquisar, minha produção monográfica será sobre os espaços da E.I. - as instituições , como são planejadas e quem participa , pois através do estudo do documento soube que se faz necessário uma equipe multidisciplinar na elaboração do projeto arquitetônico de construção das instituições de E.I. Para mim foi muito gratificante (aluna do $5^{\circ}$ semestre do curso de Pedagogia - 2008)

Diante do exposto, podemos refletir que a construção da saber numa perspectiva dialógica, de criação do concreto pensado, transformado em síntese elaborada, a busca dos percursos dos conteúdos curriculares, como temas e veredas, em relações rizomáticas de seus elementos, possam efetivar-se, em ação/reflexão/ação continuas do fazer-se educador. 
Fica aqui o desejo de que, nós educadores, compreendamos a tão repetida mensagem de Paulo Freire (1996), de que ensinar não é transmitir conhecimento e que nós educadores devemos ser mestres/aprendizes, que além de intermediar a ação pedagógica, de provocar reflexões intensas, também no ato de ensinar, constrói conhecimentos.

Para Freire (1996) o professor enquanto pesquisador é mestre/aprendiz, aquele que aprende enquanto ensina e que ensina enquanto aprende. Como afirmava Gonzaguinha, [...] viver e não ter a vergonha de ser feliz, cantar, e cantar, a beleza de ser um eterno aprendiz [...]. (GONZAGA JÚNIOR, 1982) O verdadeiro educador, na perspectiva Freiriana, deve ser epistemologicamente curioso, o que implica na "capacidade de aprender, de que decorre a de ensinar, sugere ou, mais do que isso implica a nossa habilidade de aprender a substantividade do objeto apreendido". Aprender é "construir, reconstruir, constatar para mudar, o que não se faz sem abertura ao risco e à aventura do espírito". (FREIRE, 1997, p. 74)

A experiência do estudo do meio nos possibilitou a percepção de que é imprescindível que o educador assuma suas convicções, instigado pelos desafios da prática em sala de aula, assumindo suas limitações, num esforço continuo de superá-las, como dizia Paulo Freire (1997, p. 14), "limitações que não procuro esconder em nome mesmo do respeito que me tenho e aos educandos". Desse modo fica o amadurecimento de que cabe ao mesmo, uma atuação flexível e contextualizada, um permanente diálogo com a realidade, na perpectiva de provocar uma mobilização e reconstrução de saberes e numa aprendizagem continuada, permedada pela constante reflexão na e sobre a ação.

Como afirmava Paulo Freire (1991, p. 32):

Ninguém começa a ser educador numa certa terça-feira às quatro horas da tarde. Ninguém nasce educador ou marcado para ser educador. A gente se faz educador, a gente se forma, como educador, permanentemente, na prática e na reflexão sobre a prática.

É imprescindivel a nós educadores uma prática pedagógica que num processo cíclico de ação-reflexão-ação (aproximando-se da investigação sobre a prática), possibilite a tomada de decisões e resolução de problemas durante o ato de ensino.

O oficio de ser educador em si é complexo, principalmente quando se tem por objetivo a mudança de paradigma do processo de ensinagem, numa prática pedagógica que se pretende mudança de conceitos, onde a pesquisa torna-se o fulcro do processo educativo, buscano transformar o conhecimento do senso comum em conhecimento científico, entrelaçando o saber acadêmico com a realidade. 
Como afirmou Albert Einstein, "é mais fácil desintegrar um átomo do que um preconceito", contudo não pretende-se afirmar que as mudanças não são possíveis.

A educação é obra transformadora, criadora. Ora, para criar é necessário mudar, perturbar, modificar a ordem existente Fazer alguém progredir significa modificá-lo. Por isso, a educação é um ato de desobediência e de desordem. Desordem em relação a uma ordem dada, uma pré-ordem. Uma educação autêntica reordena. É por essa razão que ela perturba, incomoda. É nessa dialética ordem-desordem que se opera o ato educativo. (GADOTTI, 1980, p. 89)

Para que a educação possa fazer-se obra transformadora, criadora, se faz mister que nós educadores estejamos abertos a refletir nossa prática, repensar o nosso modelo de prática pedagógica.

O processo de ensinagem, tendo a pesquisa como principio, deve centrase em transformar o paradigma "tradicional" de ensino e aprendizagem, num paradigma que nos possibilite voar, experimentar, criando condições de diálogo com os educandos. Numa prática que possibilite ao educador presenciar as aprendizagens significativas dos educandos, a partir do exercício das habilidades mentais na objetivação da proposta, assumindo e sistematizando os conceitos construídos e reelaborados nas discussões e apresentação dos estudos realizados.

Neste contexto a interação planejada e intencional, entre educador, aducando e objeto do conhecimento, configura-se segundo Anastasiou (2003, p. 34) "a essência da relação pedagógica".

Desse modo, são grandes os desafios e imensas as possibilidades. Urge avançar na direção de uma prática pedagógica que promova o diálogo dos educandos com o conhecimento, como base para enfrentar os dilemas e compromissos do cotidiano e das incertezas da vida. Pois conforme Demo (1985, p. 67, apud MACEDO, 2006, p. 39) "[...] o intensivo tem mil faces. Aparece e desaparece. Reflui e se esgueira. Toda felicidade tem uma pitada de amargura, como toda amargura pode ser prenúncio de alegria. 'Há o que é bom e dói, como há o que dói e é bom. Possui estruturas éticas, mas é capaz de imoralidades"' (grifo nosso), explicitando deste modo, o quanto devemos ter claro que o objetivo da pesquisa não é a busca de qualificação da realidade pesquisada, mas antes uma possível compreensão da mesma. Pois como afirma Demo (2006, p. 29), "Antes de mais nada, cientista é quem duvida do que vê, diz-se, aparece, e, ao mesmo tempo, não acredita poder afirmar algo com certeza absoluta." 


\section{Referências}

ANASTASIOU, Lea das Graças Camargo; ALVES, Leonir Pessate. Processos de ensinagem na universidade. Pressupostos para uma estratégia de trabalho em sala. Joinville, SC: UNIVILLE, 2003.

DEMO, Pedro. Educar pela pesquisa. Campinas: Autores Associados, 1997.

. Pesquisa como metodologia de trabalho. Revista de Educação AEC, Brasília, v. 21, n. 83, p. 7-11, abr.jun. 1992.

. Metodologia da investigação em educação. Curitiba: Ibpex, 2006. . Ciência e qualidade. São Paulo: Artmed,1985.

FREIRE, Paulo. A educação na cidade. São Paulo: Primavera, 1991. . Educação e mudança. Rio de Janeiro: Paz e Terra, 1979.

. Educação como prática da liberdade. 22. ed. Rio de Janeiro: Paz e Terra, 1996.

. Pedagogia da autonomia: saberes necessários à prática. Rio de Janeiro: Paz e Terra, 1997.

GADOTTI, Moacir. Educação e poder: introdução à pedagogia do conflito. São Paulo: Cortez, 1980.

GONZAGA JÚNIOR, Luiz - Gonzaguinha. O que é, o que é. In: Caminhos do coração, faixa 3. LP/CD [S.1.]: EMI-Odeon, 1982.

ILHA, Franciele Roos da Silva. A prática da pesquisa em educação: história, desafios e possibilidades. Revista Partes, São Paulo, 01 set. 2008. Disponível em: <http://www.partes.com.br/educacao/praticadapesquisa.asp $>$. Acesso em: 07 set. 2008.

MACEDO, Roberto Sidnei. Etnopesquisa crítica, etnopesquisa-formação. Brasília: Liber Livro, 2006.

BRASIL.MEC. Ministério da Educação. Currículo Nacional do Ensino Básico. Competências Essenciais. Brasília. 2000. Disponível em: $<$ http:// www.dgidc.mi-nu.pt/public/cnebindex.asp>. Acesso em: 18 ago. 2008

PEREIRA, Ana Cristina Silva de Oliveira; FONSECA, Zenilda de Jesus. Pesquisa e formação do educador: desafios e possibilidades de articulação. In: ENCONTRO DE PESQUISA EDUCACIONAL DO NORTE E NORDESTE, 18. 2007, Maceió, AL, 2007. 